\title{
Some features of the distribution of birthweight of human infants
}

\author{
R. J. PETHYBRIDGE, J. R. ASHFORD, AND J. G. FRYER \\ University of Exeter
}

\section{SUMMARY}

This paper is concerned with the distribution of birthweight of some 18,700 singleton live and still births taking place in Cornwall, Devon, Plymouth, and Exeter in 1965. Information collected as part of the statutory birth registration process was linked to the corresponding information about the birth recorded by the local authority health department. The birthweights were originally recorded in ounces, but the irregularities in the pattern of results suggest that the observations are subject to substantial observer error and are accurate at best to the nearest quarter pound.

The general form of the birthweight distribution is examined and it is shown that the overall distribution can be effectively summarized by a mixture of two normal components. Because of the inaccuracies of the basic data concerning birthweight, it is not possible to obtain reliable estimates of all the five parameters necessary to describe a mixture of two normal components. However, the distribution (which we convert to the metric scale) can be described adequately in terms of the mean and standard deviation of the primary or major component and the proportion of births weighing less than $2,000 \mathrm{~g}$, the corresponding figures for all single births being $3,380 \mathrm{~g}, 500 \mathrm{~g}$, and $2.0 \%$ respectively.

The population of single births was subdivided in turn on the basis of sex, social class, parity, and maternal age. The mean of the primary component was about $120 \mathrm{~g}$ higher in males than in females, about $130 \mathrm{~g}$ higher in parity 1 births than in parity 0 births, about $110 \mathrm{~g}$ higher in births to mothers of 30-34 years of age than in births to mothers of less than 20 years, and about $150 \mathrm{~g}$ higher in social classes 1 and 2 than in social class 5 . When two or more attributes are considered in combination, the social class gradient is present in most of the various subpopulations formed by subdivision of the population in terms of the other attributes. However, there seem to be complex interactions in terms of sex, parity, and maternal age. For example, the estimates of the mean of the primary component for males of parity 0 increase with increasing maternal age, i whereas the corresponding estimates for females of ${ }^{\circ}$ parity 0 decrease. The variability of the primary distribution is greater for males than for females and increases with decreasing social class, increasing parity, and increasing maternal age. The proportion of births weighing less than $2,000 \mathrm{~g}$ was similar ine males and females but decreased with increasing social class. In terms of parity, the proportion was higher for parity 0 than for parity 1 but subsequently increased with increasing parity. A similar pattegn exists for maternal age in male infants, the pro-portion decreasing with age to reach a minimum the 25-29 years age group and subsequently increasing as maternal age increases further. Female $\overline{0}$ infants, on the other hand, show a totally differento pattern in the lowest maternal age groups.

\section{INTRODUCTION}

The importance of birthweight as an indicator of the viability of the newborn infant is well established. In England and Wales perinatal mortality among? infants weighing less than $1,500 \mathrm{~g}$ at birth is moreo than 50 times as high as that among infants weighing between 3,000 and 4,000 $\mathrm{g}$ (Brimblecombe et al., 8 1968). The close association between birthweight $₹$ and perinatal mortality for individual births iso reflected in corresponding differences between $\vec{D}$ populations. For example, a substantial part of theo secular variation in perinatal mortality in England and Wales during recent years can be accounted for $\circ$ by changes in the proportion of low weight (less $N$ than 2,500 g) births (Ashford, Brimblecombe, and N Fryer, 1968).

As part of a study of factors affecting perinata mortality, information about births which took place in the south-west of England in 1965 has been obtained by linking data obtained by the birth registration process with corresponding information ${ }^{-}$ collected by the local authority health departments. 
On this basis, it is possible to examine the distribution of birthweight in this population in terms of some of the primary characteristics of mother and infant. This paper is concerned with the distribution of birthweight in four local authorities: Cornwall, Plymouth, Devon County, and Exeter. Analyses of other features of the data covering the remainder of the south-west region will be reported elsewhere.

Variations in birthweight distribution in terms of various characteristics of mother and infant have been reported in a variety of populations (see, for example, Abernathy, Greenberg, Grizzle, and Donnelly (1966); Butler and Alberman (1969); Kaminski, Goujard, and Rumeau-Rouquette (1973)). These studies have, however, been concerned for the most part with specific features of the distribution, such as average birthweight and the proportion of low weight (less than $2,500 \mathrm{~g}$ ) births. Little attention has been given to a full characterization of the distribution, although Ashford (1970) has demonstrated that there are systematic differences in the variability as well as in the mean. The purpose of the present paper is to examine as far as possible the variation of some of the main features of the birthweight distribution in terms of the maternal age, parity, and social class, and the sex and multiplicity of the birth.

\section{Sources of DATA}

In England and Wales there are two separate systems for recording births. The better known is the statutory birth registration system under which the mother or a close relative provides standard information about the birth to the local Registrar of Births and Deaths. If the infant is stillborn, the items recorded differ in some respects from those pertaining to live births, but in both cases the registration process is concerned essentially with non-medical information. The second system is based upon the birth notification, which is a return made by the medical attendant or midwife present during the delivery to the relevant local authority health department. The birth notification includes certain items in common with the birth certificate, notably the identification of the mother and the infant. A substantial part of the birth notification is concerned with the medical circumstances of the pregnancy, delivery, and birth. Although there is no standard format and different items are recorded in different local authorities, certain data, including birthweight and place of birth, are always included. The main object of the birth notification is to inform the local authority health department of the birth in order to set in motion procedures for the care of the mother and the infant. The birth notification documents are also used as the basis of annual returns by the local authority. Birth notifications must be returned to the local authority within 48 hours of birth. In contrast, there is a period of grace of $\mathbf{3 5}$ days for the birth registrations.

Although there is no formal link between the two recording systems, informal contacts between Registrars and health departments ensure that births recorded on either system are brought to the attention of the other and that any anomalies are followed up. Many births take place within the boundaries of a local authority other than the one in which the mother normally lives. For this reason, the birth notifications are 'transferred back' to the local authority of usual residence of the mother, which is also noted in the birth registrations. In the normal course of events, the birth notifications remain with the local authority, while the birth certificate serves as a legal document and the information contained therein forms the basis of vital statistics produced by the Office of Population, Censuses, and Surveys (OPCS).

It is an unfortunate feature of the existing procedures that much valuable information concerning the care received during the antenatal, delivery, and postnatal periods is not available to the national statistical system although recorded in a conscientious and reproducible manner by responsible persons for the local authority. The birth registration system, which was conceived largely in the first half of the nineteenth century in response to problems which no longer exist, does not provide an adequate basis for monitoring the performance of the maternity care system. Nor are the resulting data adequate for certain important research purposes. In order to bring together data about birthweight and other medical factors with information collected in the birth registration, special arrangements are required.

With the co-operation of the OPCS and the local Medical Officers of Health, arrangements were made to link together the birth registrations and birth notifications relating to all births taking place in the south-west of England during the calendar year 1965. Copies of the relevant birth notifications, identified by name of infant and date of birth, were sent to the OPCS. The birth notifications were then matched with information from the corresponding birth certificates and the results were brought together in a single document. In order to preserve the anonymity of the records, the personal identification was excluded from the combined data. In the event, the record linkage was completed successfully. The proportion of births known to either system 
which could not be traced in the other was negligible and there was good agreement between common items of information.

Apart from some very minor adjustments, the present analysis is concerned with the live and stillbirths occurring during 1965 to mothers normally resident in the Cornwall, Devon, Exeter, and Plymouth local authorities, an area which can be regarded as relatively homogeneous. For each such birth, a record was made of various items, including birthweight, sex, multiplicity of birth, social class, parity, and maternal age. All items except the first were derived from the birth certificate.

\section{ACCURACY OF RECORDED BIRTHWEIGHTS}

In 1965 the units used for recording birthweights were pounds and ounces, and the distribution obtained for singletons is presented in these terms in Table I. For the domiciliary deliveries, a simple portable spring balance calibrated in pounds and ounces was normally employed. The remainder of the deliveries took place in institutions where more sophisticated apparatus for weighing the newborn was normally available. The majority of the institutional birthweights were recorded in pounds and ounces, but in some institutions the weighing apparatus was calibrated in grammes and the results were subsequently expressed in pounds and ounces by the use of a conversion table.

Reference to Table I shows evidence of an irregular pattern of recorded birthweights. The results tend to cluster at the zero and 8 ounce points on the scale and, to a lesser extent, at the $2,4,6,10$, and 12 ounce points. For example, 920 infants were assessed as weighing exactly 8 pounds at birth, compared with
$195,292,220$, and 508 as 8 pounds $1,2,3$, and 4 ounces $\frac{3}{3}$ respectively. These irregularities are present through- $\stackrel{\square}{?}$ out the whole range of birthweights and on general $\overrightarrow{\vec{F}}$ grounds must be attributed to vagaries of the record- $\stackrel{\vec{P}}{\stackrel{9}{ }}$ ing procedure rather than to real variations within the population of births. The pattern is less pro- $\frac{\bar{D}}{\bar{D}}$ nounced among the lower birthweights, which $\frac{\bar{D}}{\widehat{D}}$ suggests that accuracy of recording is better when $\stackrel{\odot}{\propto}$ birthweight has a greater clinical significance. ® However, there are substantial systematic errors in $\vec{\circ}$ the region of 5 pounds 8 ounces, which by convention is regarded as the upper limit of 'low weight' $\vec{\omega}$ births. Because of this element of 'digit preference', $\stackrel{\circ}{\Omega}$ the recorded proportion of birthweights classed as 'less than or equal to $5 \frac{1}{2} \mathrm{lbs}$ ' (or equivalently as 'less than or equal to $2,500 \mathrm{~g}$ ) probably overestimates $\stackrel{0}{\circ}$ the true figure to some extent. The data were also subdivided in terms of place of confinement. The $\vec{O}$ irregularities were most marked for births taking 윽 place at home but were also present for hospital deliveries. An excess of births at the zero and 8 T ounce points was observed even at hospitals where $\frac{\mathbb{O}}{\mathrm{C}}$ the weighing apparatus was calibrated in grammes, presumably reflecting inadequacies in the conversion to pounds and ounces.

The pattern of results suggests that the recordee birthweights are at best accurate to the neares quarter pound; in view of the circumstances in which the measurement is made this is hardly surprising. In any reliable statistical analysis this basic inaccuracy must be recognized by the choice $\frac{\circ}{\Phi}$ of an appropriate grouping interval to 'smooth out' the irregularities. In contrast, the other attributes of the mother and infant with which the present study is concerned were obtained from the birth registration process and are known to be reliable.

TABLE I

DISTRIBUTION OF RECORDED BIRTHWEIGHT, SOUTH-WEST OF ENGLAND, 1965 Number of Singleton Live and Still Births

\begin{tabular}{|c|c|c|c|c|c|c|c|c|c|c|c|c|c|c|c|c|c|c|c|}
\hline \multicolumn{3}{|c|}{ Pounds } & & 0 & 1 & 2 & 3 & 4 & 5 & 6 & 7 & 8 & 9 & 10 & 11 & 12 & 13 & 14 & 15 \\
\hline $\begin{array}{l}0 \\
1 \\
2 \\
3 \\
4 \\
5 \\
6 \\
7 \\
8 \\
9 \\
10 \\
11 \\
12 \\
13 \\
14\end{array}$ & $\begin{array}{l}\ldots \\
\cdots \\
\cdots \\
\cdots \\
\cdots \\
\cdots \\
\cdots\end{array}$ & $\begin{array}{l}\cdots \\
\cdots \\
\cdots \\
\cdots \\
\cdots \\
\cdots \\
\cdots \\
\cdots \\
\cdots \\
\cdots\end{array}$ & $\begin{array}{l}\cdots \\
\cdots \\
\cdots \\
\cdots \\
\cdots \\
\cdots \\
\cdots \\
\cdots \\
\cdots \\
\cdots \\
\cdots\end{array}$ & $\begin{array}{r}0 \\
6 \\
18 \\
14 \\
22 \\
66 \\
323 \\
914 \\
920 \\
395 \\
88 \\
17 \\
2 \\
0 \\
1\end{array}$ & $\begin{array}{r}0 \\
1 \\
4 \\
6 \\
14 \\
37 \\
101 \\
225 \\
195 \\
83 \\
12 \\
1 \\
0 \\
0 \\
0\end{array}$ & $\begin{array}{r}0 \\
1 \\
2 \\
8 \\
16 \\
42 \\
183 \\
390 \\
292 \\
118 \\
26 \\
3 \\
0 \\
0 \\
0\end{array}$ & $\begin{array}{r}0 \\
1 \\
2 \\
5 \\
19 \\
46 \\
157 \\
286 \\
220 \\
72 \\
9 \\
2 \\
0 \\
0 \\
0\end{array}$ & $\begin{array}{r}0 \\
3 \\
6 \\
9 \\
16 \\
60 \\
337 \\
697 \\
508 \\
142 \\
23 \\
3 \\
0 \\
0 \\
0\end{array}$ & $\begin{array}{r}0 \\
0 \\
2 \\
6 \\
14 \\
41 \\
160 \\
311 \\
200 \\
53 \\
11 \\
1 \\
0 \\
0 \\
0\end{array}$ & $\begin{array}{r}0 \\
2 \\
4 \\
8 \\
15 \\
67 \\
205 \\
417 \\
230 \\
69 \\
6 \\
0 \\
0 \\
0 \\
0\end{array}$ & $\begin{array}{r}0 \\
2 \\
2 \\
9 \\
19 \\
59 \\
172 \\
291 \\
166 \\
45 \\
4 \\
2 \\
0 \\
0 \\
0\end{array}$ & $\begin{array}{r}0 \\
3 \\
10 \\
14 \\
47 \\
106 \\
504 \\
817 \\
485 \\
145 \\
18 \\
2 \\
0 \\
0 \\
0\end{array}$ & $\begin{array}{r}0 \\
1 \\
4 \\
2 \\
17 \\
78 \\
215 \\
289 \\
147 \\
35 \\
8 \\
0 \\
0 \\
0 \\
0\end{array}$ & $\begin{array}{r}0 \\
3 \\
4 \\
6 \\
23 \\
98 \\
299 \\
369 \\
198 \\
42 \\
7 \\
4 \\
0 \\
0 \\
0\end{array}$ & $\begin{array}{r}0 \\
4 \\
2 \\
6 \\
15 \\
68 \\
222 \\
279 \\
110 \\
22 \\
2 \\
1 \\
0 \\
0 \\
0\end{array}$ & $\begin{array}{r}1 \\
8 \\
8 \\
7 \\
39 \\
135 \\
496 \\
626 \\
288 \\
91 \\
16 \\
2 \\
0 \\
0 \\
0\end{array}$ & $\begin{array}{r}0 \\
2 \\
7 \\
5 \\
30 \\
92 \\
256 \\
246 \\
122 \\
18 \\
4 \\
0 \\
0 \\
0 \\
0\end{array}$ & $\begin{array}{r}0 \\
2 \\
4 \\
14 \\
26 \\
106 \\
315 \\
330 \\
146 \\
25 \\
2 \\
1 \\
0 \\
0 \\
0\end{array}$ & $\begin{array}{r}2 \\
1 \\
3 \\
7 \\
32 \\
81 \\
228 \\
236 \\
78 \\
10 \\
4 \\
0 \\
0 \\
0 \\
0\end{array}$ \\
\hline
\end{tabular}

Total, including 51 with unknown birthweight, 18,696 


\section{The Form of the Distribution of Birthweight}

Following a review of data concerning birthweight derived from a wide variety of sources, Brimblecombe, Ashford, and Fryer (1968) have suggested that the distribution of birthweight for live and stillbirths in a naturally occurring population can be adequately represented by a mixture of two normal or Gaussian populations. The great majority of the births belong to the primary distribution, with a mean birthweight of about $3,350 \mathrm{~g}$, while some $5-10 \%$ belong to the secondary distribution, with a mean of about $2,000 \mathrm{~g}$. The presence of these two populations can be detected most readily by a plot of the cumulative frequency of birthweight using a non-uniform 'probability' scale. The corresponding data for the 1965 births in Cornwall, Devon, Exeter, and Plymouth are shown in the Figure, single births and twins being shown separately. For both single and mult:ple births, the distribution consists of two distinct straight lines corresponding to the two Gaussian populations. This shows the characteristic pattern (Ashford, 1970) and confirms that a representation of the birthweight distribution in terms of a mixture of two normal components provides an

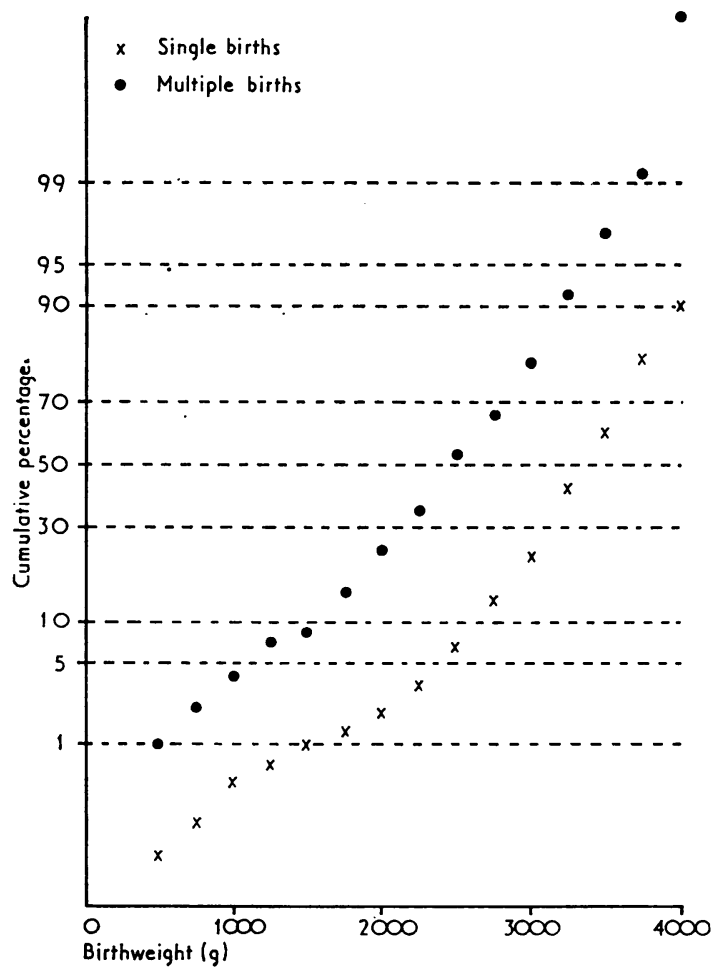

FIGURE Cumulative distributions of live births and late fetal deaths, south-west of England, 1965 excellent descriptive model. This representation is found to apply both to complete naturally occurring populations and to the subpopulations obtained by subdividing such populations in terms of factors such as multiplicity of birth, social class, parity, maternal age, and sex. It should, however, be borne in mind that, in common with many similar models, the two-component representation represents a simplification of the real-life situation, the biological significance of which has not been established. As expected, the distribution for multiple births is clearly separated from that for single births, with a difference of some $800 \mathrm{~g}$ between the corresponding lines. In view of this and because of the very small numbers involved, the multiple births have been excluded from the subsequent analysis.

A mixture of two normal distributions may be defined in terms of five parameters, the mean and standard deviation of each component and the proportion of one or other component in the mixture. In theory, the estimation of these five parameters from grouped data is a straightforward problem, provided that the grouping is sufficiently coarse (see Fryer and Robertson, 1972), although there are certain computational difficulties associated with the need to employ an iterative procedure to determine the optimum value of the object function. In practice, however, the inaccuracy of the basic data and the fact that a very large part of the population belongs to one component militate against the calculation of reliable estimates of all five parameters. In the event, it was found possible to determine valid estimates of the mean and standard deviations of the primary distribution, while the estimates of the remaining three parameters were unreliable. For this reason, it has been necessary to adopt an alternative and less elegant representation of the birthweight distribution. Preliminary studies have demonstrated that virtually all the births weighing more than $2,636 \mathrm{~g}\left(5 \mathrm{lb} 13 \frac{1}{2} \mathrm{oz}\right.$ ) belong to the primary distribution and virtually all the births weighing less than $2,000 \mathrm{~g}$ belong to the secondary distribution. The mean and standard deviation of the primary distribution, denoted $m$ and $s$ respectively, were estimated from the birthweight distribution above $2,636 \mathrm{~g}$, and the grouping of the data was arranged to minimize the effect of irregularities due to digit preference. The lower part of the birthweight distribution has been characterized by the proportion of births weighing less than $2,000 \mathrm{~g}$, denoted $p$. This latter quantity reflects each of the three remaining parameters in the five parameter representation and provides a useful measure of the lower 'tail' distribution in its own right. We have chosen the dividing line 2,000 $\mathrm{g}$ 
rather than the conventional $2,500 \mathrm{~g}$ largely because a substantial proportion of the birthweights between 2,000 and $2,500 \mathrm{~g}$ are associated with the primary distribution. The mean and standard deviation of the primary distribution of single births were respectively $3,383 \mathrm{~g}$ and $500 \mathrm{~g}$ and the proportion of births weighing less than $2,000 \mathrm{~g}$ was $2.0 \%$. The corresponding figures for the multiple births, which consisted of 213 sets of twins and three sets of triplets, were found to be $2,570 \mathrm{~g}, 530 \mathrm{~g}$, and $24 \%$, using a somewhat lower truncation point.

\section{Association of Personal Attributes with BIRTHWEIGHT}

In order to assess the association of various personal characteristics with birthweight, the population was subdivided according to each of the attributes of interest in turn. In each such analysis the birthweight distribution conformed to the pattern described above. The results obtained are summarized in terms of the three descriptive parameters in Table II, which also shows the standard errors of the individual estimates.

In terms of the primary distribution, the mean for males is some $120 \mathrm{~g}$ greater than for females, while the standard deviation is some $30 \mathrm{~g}$ greater. Thus, in this primary distribution, the males are both heavier on average and more variable in weight than the females. On the other hand, there is no appreciable difference between the two sexes in the proportion of births weighing less than $2,000 \mathrm{~g}$. For either sex, the mean of the primary distribution of illegitimate births is lower and the standard deviation of the primary distribution and the proportion of births weighing less than $2,000 \mathrm{~g}$ are higher than in the corresponding group of legitimate births. There is a well-defined tendency for the mean of the primary distribution to increase with increasing social class. The differences between classes 1 and 2 (taken together because of the small numbers involved) and class 3 is about $70 \mathrm{~g}$, while that between 3 and 4 is only $25 \mathrm{~g}$, and between 4 and 5 is $50 \mathrm{~g}$. The variability of the primary distribution, on the other hand, decreases slightly with increasing social class. There are, however, very marked differences in the proportions of low weight births, only $1.3 \%$ being recorded for social classes 1 and 2, compared with $2 \cdot 0 \%$ and $2 \cdot 3 \%$ for social classes 3 and 4 respectively, and $3.0 \%$ for social class 5 . The trend of these results is the same as that of the mean of the primary distribution, but the differences are much too great to be merely a reflection of corresponding differences in the lower 'tail' of the primary distribution.

In terms of birth order, the mean of the primary distribution is about $130 \mathrm{~g}$ higher for parity 1 than for parity 0 and is about $20 \mathrm{~g}$ higher for parities 20 and 3 than for parity 1 . Parity 4, on the other hand, is some $15 \mathrm{~g}$ below parity 1 and parity 5 or more is about $25 \mathrm{~g}$ less than parity 4 . However, the standard

TABLE II

ANALYSIS IN TERMS OF SEPARATE ATTRIBUTES, SINGLE LIVE AND STILL BIRTHS, SOUTH-WEST OF ENGLAND, 1965

\begin{tabular}{|c|c|c|c|c|c|c|c|c|c|c|}
\hline \multirow{2}{*}{\multicolumn{2}{|c|}{ Attribute }} & \multirow{2}{*}{\multicolumn{2}{|c|}{ Class }} & \multirow[b]{2}{*}{ No. of Births } & \multicolumn{6}{|c|}{ Estimates (and Standard Errors) } \\
\hline & & & & & $m$ & (g) & & (g) & $p$ & $(\%)$ \\
\hline Sex & $\cdots$ & $\begin{array}{l}\text { Males (all) } \\
\text { Males (legi } \\
\text { Males (ille } \\
\text { Females (a } \\
\text { Females (le } \\
\text { Females (il }\end{array}$ & $\begin{array}{l}\text { itimate) } \\
\text { gitimate) } \\
\text { ii) } \\
\text { egitimate): } \\
\text { legitimate) }\end{array}$ & $\begin{array}{r}9,695 \\
8,965 \\
730 \\
8,950 \\
8,310 \\
640\end{array}$ & $\begin{array}{l}3,445 \\
3,454 \\
3,334 \\
3,323 \\
3,327 \\
3,268\end{array}$ & $\begin{array}{l}(7) \\
(7) \\
(29) \\
(7) \\
77) \\
(30)\end{array}$ & $\begin{array}{l}505 \\
503 \\
512 \\
472 \\
472 \\
476\end{array}$ & $\begin{array}{l}(5) \\
(6) \\
(22) \\
(6) \\
(6) \\
(23)\end{array}$ & $\begin{array}{l}1 \cdot 9 \\
1 \cdot 9 \\
2 \cdot 3 \\
2 \cdot 1 \\
2 \cdot 0 \\
3 \cdot 1\end{array}$ & $\begin{array}{l}(0 \cdot 1) \\
(0 \cdot 1) \\
(0 \cdot 6) \\
(0 \cdot 2) \\
(0 \cdot 2) \\
(0 \cdot 7)\end{array}$ \\
\hline Social class & $\cdots$ & $\begin{array}{l}1 \text { and } 2 \\
3 \ldots \\
4 \ldots \\
5 \\
\text { Other }\end{array}$ & $\begin{array}{l}\ddot{*} \\
\ddot{*} \\
\ddot{*}\end{array}$ & $\begin{array}{l}3,602 \\
8,176 \\
2,911 \\
1,357 \\
2,599\end{array}$ & $\begin{array}{l}\mathbf{3}, \mathbf{4 4 8} \\
\mathbf{3}, \mathbf{3 7 7} \\
\mathbf{3}, \mathbf{3 5 3} \\
\mathbf{3}, \mathbf{3 0 0} \\
\mathbf{3 , 3 8 1}\end{array}$ & $\begin{array}{l}(10) \\
(8) \\
(14) \\
(23) \\
(13)\end{array}$ & $\begin{array}{l}486 \\
496 \\
505 \\
518 \\
480\end{array}$ & 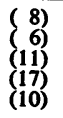 & $\begin{array}{l}1 \cdot 3 \\
2 \cdot 0 \\
2 \cdot 3 \\
3 \cdot 0 \\
1 \cdot 9\end{array}$ & $\begin{array}{l}(0 \cdot 2) \\
(0 \cdot 2) \\
(0 \cdot 3) \\
(0 \cdot 5) \\
(0 \cdot 3)\end{array}$ \\
\hline Parity & $\ldots$ & $\begin{array}{l}0 \ldots \\
1 \ldots \\
2 \ldots \\
3 \ldots \\
4 \ldots \\
5 \text { or more } \\
\text { Unknown }\end{array}$ & 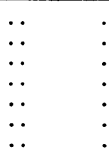 & $\begin{array}{r}6,397 \\
5,367 \\
2,915 \\
1,354 \\
571 \\
704 \\
1,337\end{array}$ & $\begin{array}{l}\mathbf{3 , 3 0 8} \\
\mathbf{3 , 4 3 7} \\
\mathbf{3 , 4 5 8} \\
\mathbf{3 , 4 5 9} \\
\mathbf{3 , 4 2 2} \\
\mathbf{3 , 3 9 6} \\
\mathbf{3 , 2 9 9}\end{array}$ & $\begin{array}{l}(8) \\
(9) \\
(12) \\
(17) \\
(36) \\
(34) \\
(22)\end{array}$ & $\begin{array}{l}464 \\
488 \\
500 \\
489 \\
573 \\
573 \\
502\end{array}$ & $\begin{array}{l}(7) \\
7) \\
(10) \\
(14) \\
(28) \\
(26) \\
(17)\end{array}$ & $\begin{array}{l}2 \cdot 4 \\
1 \cdot 2 \\
1 \cdot 6 \\
2 \cdot 6 \\
2 \cdot 5 \\
3 \cdot 5 \\
2 \cdot 6\end{array}$ & $\begin{array}{l}(0.2) \\
(0.1) \\
(0.2) \\
(0.4) \\
(0.7) \\
(0.6) \\
(0.4)\end{array}$ \\
\hline Maternal age (yr) & $\ldots$ & $\begin{array}{l}<20 \\
20-24 \\
25-29 \\
30-34 \\
35-39 \\
>39\end{array}$ & $\begin{array}{l}\cdots \\
\cdots \\
\cdots \\
\cdots \\
\cdots\end{array}$ & $\begin{array}{r}1,871 \\
6,273 \\
5,542 \\
2,949 \\
1,504 \\
506\end{array}$ & $\begin{array}{l}\mathbf{3}, 319 \\
3,359 \\
3,413 \\
3,427 \\
3,394 \\
3,358\end{array}$ & $\begin{array}{l}(15) \\
(8) \\
9) \\
(13) \\
(23) \\
(34)\end{array}$ & $\begin{array}{l}451 \\
474 \\
490 \\
519 \\
566 \\
510\end{array}$ & $\begin{array}{l}(12) \\
(7) \\
(7) \\
(10) \\
(17) \\
(27)\end{array}$ & $\begin{array}{l}2 \cdot 4 \\
1 \cdot 9 \\
1 \cdot 5 \\
1 \cdot 9 \\
3 \cdot 3 \\
3 \cdot 4\end{array}$ & $\begin{array}{l}(0 \cdot 4) \\
(0 \cdot 2) \\
(0 \cdot 2) \\
(0 \cdot 3) \\
(0 \cdot 5) \\
(0 \cdot 8)\end{array}$ \\
\hline
\end{tabular}


TABLE III

ANALYSES OF BIRTHWEIGHT DISTRIBUTION IN TERMS OF SEX, PARITY, AND MATERNAL AGE, SINGLE LIVE AND STILL BIRTHS, SOUTH-WEST OF ENGLAND, 1965

Estimates (and Standard Errors) of the Mean of the Primary Component

(a) Males

\begin{tabular}{|c|c|c|c|c|c|c|c|c|c|c|c|c|c|c|}
\hline \multirow{3}{*}{$\begin{array}{l}\text { Maternal } \\
\text { Age (yr) }\end{array}$} & \multicolumn{14}{|c|}{ Parity } \\
\hline & \multicolumn{2}{|c|}{0} & \multicolumn{2}{|c|}{1} & \multicolumn{2}{|c|}{2} & \multicolumn{2}{|c|}{3} & \multicolumn{2}{|c|}{4} & \multicolumn{2}{|c|}{5 or more } & \multicolumn{2}{|c|}{ All } \\
\hline & $\begin{array}{r}3,328 \\
3,370 \\
3,363 \\
3,440 \\
3,483\end{array}$ & $\begin{array}{l}(24) \\
(15) \\
(24) \\
(36) \\
(61)\end{array}$ & $\begin{array}{r}3,522 \\
3,510 \\
3,533 \\
3,495 \\
3,466\end{array}$ & $\begin{array}{l}(41) \\
(19) \\
(19) \\
(33) \\
(66)\end{array}$ & $\begin{array}{l}3,492 \\
3,554 \\
3,536 \\
3,415 \\
3,409\end{array}$ & $\begin{array}{r}(38) \\
(23) \\
(30) \\
(70) \\
(101)\end{array}$ & $\begin{array}{l}3,470 \\
3,531 \\
3,543 \\
3,415 \\
3,376\end{array}$ & $\begin{array}{r}(84) \\
(43) \\
(39) \\
(84) \\
(130)\end{array}$ & $\begin{array}{l}3,544 \\
3,492 \\
3,445\end{array}$ & $\begin{array}{r}(67) \\
(54) \\
(109)\end{array}$ & $\begin{array}{l}3,361 \\
3,473 \\
3,521 \\
3,474\end{array}$ & $\begin{array}{r}(147) \\
(108) \\
(80) \\
(64)\end{array}$ & $\begin{array}{l}3,349 \\
\mathbf{3 , 4 2 2} \\
\mathbf{3 , 4 8 5} \\
\mathbf{3 , 4 9 4} \\
\mathbf{3 , 4 4 7} \\
\mathbf{3 , 4 0 9}\end{array}$ & $\begin{array}{l}(20) \\
(11) \\
(12) \\
(17) \\
(32) \\
(45)\end{array}$ \\
\hline All $\ldots$ & 3,367 & (11) & 3,514 & (12) & 3,519 & (16) & 3,502 & (26) & 3,509 & (49) & 3,471 & (49) & 3,445 & (7) \\
\hline
\end{tabular}

(b) Females

\begin{tabular}{|c|c|c|c|c|c|c|c|c|c|c|c|c|c|c|}
\hline \multirow{3}{*}{$\begin{array}{c}\begin{array}{c}\text { Maternal } \\
\text { Age (yr) }\end{array} \\
\\
20 \ldots \\
20-24 \\
25-29 \\
30-34 \\
35-39 \\
>39 \ldots\end{array}$} & \multicolumn{14}{|c|}{ Parity } \\
\hline & \multicolumn{2}{|c|}{0} & \multicolumn{2}{|c|}{1} & \multicolumn{2}{|c|}{2} & \multicolumn{2}{|c|}{3} & \multicolumn{2}{|c|}{4} & \multicolumn{2}{|c|}{5 or more } & \multicolumn{2}{|c|}{ All } \\
\hline & $\begin{array}{r}3,249 \\
3,254 \\
3,232 \\
3,209 \\
3,079\end{array}$ & $\begin{array}{r}(30) \\
(18) \\
(30) \\
(74) \\
(165)\end{array}$ & $\begin{array}{l}\mathbf{3}, 422 \\
3,357 \\
3,378 \\
3,327 \\
3,351\end{array}$ & $\begin{array}{l}(40) \\
(20) \\
(18) \\
(39) \\
(57)\end{array}$ & $\begin{array}{l}\mathbf{3}, 407 \\
\mathbf{3 , 4 0 8} \\
\mathbf{3 , 4 0 7} \\
\mathbf{3 , 3 8 2} \\
\mathbf{3 , 0 3 3}\end{array}$ & $\begin{array}{r}(32) \\
(26) \\
(38) \\
(57) \\
(274)\end{array}$ & $\begin{array}{l}\mathbf{3 , 3 8 2} \\
\mathbf{3 , 4 1 8} \\
3,449 \\
3,418\end{array}$ & $\begin{array}{l}(45) \\
(39) \\
(39) \\
(51)\end{array}$ & $\begin{array}{l}3,316 \\
3,386 \\
3,312\end{array}$ & $\begin{array}{r}(78) \\
(75) \\
(140)\end{array}$ & $\begin{array}{l}3,244 \\
3,362 \\
3,331 \\
3,368\end{array}$ & $\begin{array}{r}(151) \\
(59) \\
(79) \\
(82)\end{array}$ & $\begin{array}{l}3,287 \\
3,299 \\
3,345 \\
3,358 \\
3,348 \\
3,308\end{array}$ & $\begin{array}{l}(22) \\
(12) \\
(12) \\
(19) \\
(51) \\
(51)\end{array}$ \\
\hline All $\ldots$ & 3,243 & (14) & 3,363 & (12) & 3,395 & (17) & 3,422 & (22) & 3,349 & (47) & 3,343 & (40) & 3,323 & (7) \\
\hline
\end{tabular}

TABLE IV

ANALYSES OF BIRTHWEIGHT DISTRIBUTION IN TERMS OF SEX, PARITY, AND MATERNAL AGE, SINGLE LIVE AND STILL BIRTHS, SOUTH-WEST OF ENGLAND, 1965

Estimates (and Standard Errors) of the Percentage of Low-Weight Births

(a) Males

\begin{tabular}{|c|c|c|c|c|c|c|c|c|c|c|c|c|c|c|}
\hline \multirow{3}{*}{$\begin{array}{l}\begin{array}{c}\text { Maternal } \\
\text { Age (yr) }\end{array} \\
\\
20 \\
20-24 \\
25-29 \\
30-34 \\
35-39 \\
>39 \ldots\end{array}$} & \multicolumn{14}{|c|}{ Parity } \\
\hline & \multicolumn{2}{|c|}{0} & \multicolumn{2}{|c|}{1} & \multicolumn{2}{|c|}{2} & \multicolumn{2}{|c|}{3} & \multicolumn{2}{|c|}{4} & \multicolumn{2}{|c|}{5 or more } & \multicolumn{2}{|c|}{ All } \\
\hline & $\begin{array}{l}3 \cdot 6 \\
1 \cdot 4 \\
2 \cdot 1 \\
3 \cdot 1 \\
5 \cdot 1 \\
5 \cdot 0\end{array}$ & $\begin{array}{l}(0 \cdot 8) \\
(0 \cdot 3) \\
(0 \cdot 5) \\
(1 \cdot 1) \\
(2 \cdot 5) \\
(4 \cdot 9)\end{array}$ & $\begin{array}{l}2 \cdot 1 \\
1 \cdot 1 \\
0 \cdot 8 \\
1 \cdot 0 \\
5 \cdot 0 \\
5 \cdot 3\end{array}$ & $\begin{array}{l}(1 \cdot 2) \\
(0 \cdot 3) \\
(0 \cdot 3) \\
(0 \cdot 5) \\
(1 \cdot 8) \\
(3 \cdot 6)\end{array}$ & $\begin{array}{l}2.2 \\
1.4 \\
1.5 \\
1.7 \\
4.0\end{array}$ & $\begin{array}{l}(0.8) \\
(0.5) \\
(0.6) \\
(1.0) \\
(2.8)\end{array}$ & $\begin{array}{l}5 \cdot 6 \\
2 \cdot 8 \\
2 \cdot 8 \\
2 \cdot 4 \\
2 \cdot 0\end{array}$ & $\begin{array}{l}(2 \cdot 7) \\
(1 \cdot 1) \\
(1 \cdot 1) \\
(1 \cdot 4) \\
(2 \cdot 0)\end{array}$ & $\begin{array}{l}4 \cdot 4 \\
0 \cdot 0 \\
2 \cdot 2 \\
0 \cdot 0\end{array}$ & $\begin{array}{l}(2 \cdot 5) \\
(1 \cdot 5) \\
(-)\end{array}$ & $\begin{array}{l}2.0 \\
3.0 \\
1.5 \\
1.6\end{array}$ & $\begin{array}{l}(2 \cdot 0) \\
(1 \cdot 7) \\
(1 \cdot 0) \\
(1 \cdot 6)\end{array}$ & $\begin{array}{l}3.2 \\
1.5 \\
1.5 \\
1.8 \\
2.8 \\
3.6\end{array}$ & $\begin{array}{l}(0 \cdot 0) \\
(0 \cdot 2) \\
(0 \cdot 2) \\
(0 \cdot 3) \\
(0 \cdot 6) \\
(1 \cdot 2)\end{array}$ \\
\hline All .. & $2 \cdot 2$ & $(0 \cdot 3)$ & $1 \cdot 3$ & $(0 \cdot 2)$ & $1 \cdot 7$ & $(0 \cdot 3)$ & 2.9 & $(0.6)$ & $1 \cdot 7$ & $(0 \cdot 8)$ & $2 \cdot 0$ & $(0 \cdot 7)$ & 1.9 & $(0 \cdot 1)$ \\
\hline
\end{tabular}

(b) Females

\begin{tabular}{|c|c|c|c|c|c|c|c|c|c|c|c|c|c|c|}
\hline \multirow{3}{*}{$\begin{array}{l}\begin{array}{c}\text { Maternal } \\
\text { Age (yr) }\end{array} \\
\\
<20 \ldots \\
20-24 \\
25-29 \\
30-34 \\
35-39 \\
>39 \ldots\end{array}$} & \multicolumn{14}{|c|}{ Parity } \\
\hline & \multicolumn{2}{|c|}{0} & \multicolumn{2}{|c|}{1} & \multicolumn{2}{|c|}{2} & \multicolumn{2}{|c|}{3} & \multicolumn{2}{|c|}{4} & \multicolumn{2}{|c|}{5 or more } & \multicolumn{2}{|c|}{ All } \\
\hline & $\begin{array}{l}1 \cdot 7 \\
2 \cdot 7 \\
2.4 \\
2.4 \\
4.9 \\
9 \cdot 1\end{array}$ & $\begin{array}{l}(0.6) \\
(0.4) \\
(0.6) \\
(1 \cdot 1) \\
(2 \cdot 4) \\
(6 \cdot 1)\end{array}$ & $\begin{array}{l}0.8 \\
1.4 \\
0.6 \\
1.3 \\
3.7 \\
2.9\end{array}$ & $\begin{array}{l}(0 \cdot 8) \\
(0 \cdot 4) \\
(0 \cdot 2) \\
(0 \cdot 6) \\
(1 \cdot 8) \\
(2 \cdot 9)\end{array}$ & $\begin{array}{l}1 \cdot 4 \\
1 \cdot 2 \\
2 \cdot 1 \\
1 \cdot 7 \\
1 \cdot 9\end{array}$ & $\begin{array}{l}(0 \cdot 7) \\
(0 \cdot 5) \\
(0 \cdot 8) \\
(1 \cdot 0) \\
(1 \cdot 9)\end{array}$ & $\begin{array}{l}1.3 \\
0.9 \\
1.0 \\
6.0 \\
0.0\end{array}$ & $\begin{array}{l}(1 \cdot 3) \\
(0 \cdot 6) \\
(0 \cdot 7) \\
(2 \cdot 1) \\
(-)\end{array}$ & $\begin{array}{l}4 \cdot 9 \\
3.8 \\
0.0 \\
8.0\end{array}$ & $\begin{array}{l}(2 \cdot 4) \\
(2 \cdot 1) \\
(5 \cdot 4)\end{array}$ & $\begin{array}{l}3.5 \\
2.7 \\
7.0 \\
1.6\end{array}$ & $\begin{array}{l}(2 \cdot 4) \\
(1 \cdot 5) \\
(2 \cdot 4) \\
(1 \cdot 6)\end{array}$ & $\begin{array}{l}1 \cdot 6 \\
2 \cdot 2 \\
1 \cdot 5 \\
2 \cdot 0 \\
3 \cdot 9 \\
3 \cdot 2\end{array}$ & $\begin{array}{l}(0.4) \\
(0.3) \\
(0.2) \\
(0.4) \\
(0.7) \\
(1.1)\end{array}$ \\
\hline All $\quad \ldots$ & $2 \cdot 6$ & $(0 \cdot 3)$ & $1 \cdot 2$ & $(0 \cdot 2)$ & 1.5 & $(0 \cdot 3)$ & 1.9 & $(0.5)$ & $3 \cdot 3$ & $(1 \cdot 1)$ & $4 \cdot 0$ & $(1 \cdot 0)$ & $2 \cdot 1$ & $(0 \cdot 2)$ \\
\hline
\end{tabular}


errors of these estimates rise sharply as parity increases. The variability of the primary distribution tends to increase with increasing parity, from $465 \mathrm{~g}$ for parity 0 to about $570 \mathrm{~g}$ for parity 5 or more. The proportion of births weighing less than $2,000 \mathrm{~g}$ decreases from $2.4 \%$ for parity 0 to $1 \cdot 2 \%$ for parity 1 but subsequently increases with increasing parity. When the data are subdivided in terms of maternal age, the mean of the primary distribution tends to increase with increasing maternal age up to 30-34 years and then to decrease, whereas, apart from the highest age group, the standard deviation increases with increasing maternal age throughout the range. The proportion of low weight births falls from $2.4 \%$ for maternal ages of less than 20 years to $1.5 \%$ for $25-29$ years but subsequently increases with increasing maternal age to $3 \cdot 4 \%$ for births to mothers of more than 39 years of age.

Our analysis is concerned with observational data and some of the factors considered are known to be closely associated. For example, it can be asserted on general grounds that a positive correlation must exist between maternal age and parity. For this reason, the data have been further subdivided in terms of two, three, and four factors simultaneously, and the birthweight distribution in each of these subpopulations has been assessed. The social class gradients noted in the analysis of this factor separately persist when the data are subdivided by parity, maternal age, and sex. The results presented in Tables III and IV are therefore concerned solely with the simultaneous variation of the latter three factors, all social classes being pooled together in the interests of simplicity of presentation.

Table III refers to the mean of the primary component of the distribution, and the results listed in the right-hand column of this Table show that the same pattern of variation with maternal age applies to both males and females. The final row of this Table indicates that the same remark applies to the variation of the mean of the distribution in terms of parity. However, when the three-factor combinations are considered, the situation is more complex. For example, the pattern of variation with maternal age for parity 0 births for males is very different from that for females. Thus, for males, the mean tends to increase with increasing maternal age, whereas the females show the reverse trend, the differences between the results for the two sexes increasing very sharply with increasing maternal age. The number of cases involved tend to fall with increasing parity and maternal age and the resulting increase in the standard errors of the estimates tend to obscure any trends which may be present in the upper parts of the range.
Table IV shows the proportions of birthweights of $z$ $2,000 \mathrm{~g}$ or less. In males, this proportion tends to fall $\stackrel{\mathbb{Q}}{\stackrel{2}{2}}$ sharply with increasing maternal age, reaching a minimum in the 25-29 years age group but subse- $\stackrel{0}{\rightarrow}$ quently rising again as maternal age increases further. Females show a similar trend for maternal 흘 ages above 25 years, but the pattern among the $\frac{\bar{c}}{\vec{D}}$ lower maternal age groups is different. When the $\stackrel{\varnothing}{\unrhd}$ males are subdivided in terms of parity, a similar trend exists for parities 0,1 , and 2 but not for parity 3,4 or 5 or more. On the other hand, the results for females in the various parities do not differ appreciably from the trend for all parities. For most age-parity combinations with these sample sizes, the differences in the estimates for males and females lie within the conventional limits of statistical $\underset{\infty}{N}$ significance. However, this is not true for all, since on the basis of difference in proportions plus or $\overrightarrow{0}$ minus 2.5 times the standard errors, the parity 0 음 maternal age group $20-24$ produces the interval $\rightarrow$ $(+0 \cdot 05,+2 \cdot 55)$.

\section{Discussion}

The main objective of the present paper is t $8 \overrightarrow{0}$ summarize the basic features of the birthweigh $\rightarrow$ distribution in an adequate and economical wap and to describe variations in the distribution i terms of certain characteristics of mother and infant. Because of the form of the distribution, conventional parameters such as the mean and the variance do not provide a satisfactory representation. Whatever the underlying explanation, birthweight distributions in naturally occurring populations correspond very closely to a mixture of normal distributions and the five parameters necessary to characterize a mixture of two such distributions embodying virtually all the available information concerning differences between and within populations. It is unfortunate that our data do not permit all five parameters to be estimated simultaneously, but the three-parameter approach followed in the paper provides a reasonably good substitute.

In our analysis we have subdivided the population of live and still births in terms of various characteristics of mother and infant and have carried out a $N$ separate analysis for each subpopulation. This approach permits a perfectly satisfactory comparison of different subgroups in our particular population, $\omega$ but when the results are assessed in terms of specific characteristics, the possibility must be borne in 0 mind that apparent variations in terms of one $\mathbb{D}$ characteristic may merely reflect corresponding? variations in a second characteristic which happens to be associated with the first. Family structure is 
known to vary with social class and hence the observed differences in terms of parity and maternal age may reflect, at least to some extent, differences in social class. This reservation does not, however, apply to variations in terms of the sex of the infant as the proportions of male and female births are the same in all the social class, maternal age, and parity categories. In order to determine to what extent variations in birthweight are associated with each specific characteristic considered in the analysis, an approach on the lines of an analysis of variance for several parameters involving all the observations is required. However, the form of the birthweight distribution is inappropriate for application of the standard statistical techniques if the secondary distribution is not negligible, although some authors (see Goldstein's contribution in Butler and Alberman (1969)) have analysed birthweight data in these terms. We are currently trying to develop a more appropriate method of statistical analysis $a$ priori, although it does not follow that this will produce substantially different conclusions. In the meantime, however, the differences between the subpopulations do provide a general indication of the association of birthweight with the characteristics with which we have been concerned.

Our analysis has revealed consistent differences in birthweight distribution between the male and female infants. Thus, the mean and the variance of the primary component for males were both higher than the corresponding parameters for females, whereas the proportion of birthweights of less than $2,000 \mathrm{~g}$ was slightly lower. The greater variability of birthweight among males reflects a general tendency which holds for many attributes of human subjects. The results obtained by a further subdivision of the population in terms of parity and maternal age suggest that different patterns of variation exist for male and female births which may be less well known. Whether this is due to differences in aspects of fetal development or in spontaneous abortion rates in the first $\mathbf{2 7}$ weeks of gestation it is not possible to say (the registration process applies only to infants surviving for 28 weeks or more after conception).

The strong social class gradient noted in our study is consistent with the findings of Butler and Alberman (1969). However, it is not possible to determine to what extent the disadvantage suffered by the lower social classes is associated with adverse environmental conditions as opposed to possible differences in genetic characteristics. Zero parity, high parity, and high maternal age, which have been found to be associated with a low mean birthweight of the primary component and a high proportion of births weighing less than $2,000 \mathrm{~g}$ in our analysis, have also been identified as being associated with a tendency to low birthweight in many other studies of the perinatal period reported in the literature. However, our results also show that the variability of the primary component tends to increase with increasing parity and maternal age and decreasing social class.

The standard deviation of the primary distribution is typically of the order of $500 \mathrm{~g}$. When a particular subpopulation is considered, the general theory of the normal distribution suggests that some $95 \%$ of the primary component lies within $\pm 1,000 \mathrm{~g}$ of the mean. In contrast, the differences between the means of the subpopulations are of the order of only 100-150 g. Thus, there is a great degree of overlap, and a classification in terms of social class, parity, and maternal age clearly does not provide an effective indicator of the weight of an individual infant. Other factors such as birthweights of previous infants (which were not available in the present study) are likely to be much more important as discriminators in terms of potential low birthweight. It follows that 'booking policies' for higher grade maternity care based solely on the maternal characteristics examined in this analysis are likely to be inefficient in identifying mothers who are likely to give birth to low-weight infants. In this context it must also be borne in mind that the relation between perinatal mortality and birthweight is not constant among subpopulations as defined in our analysis (Ashford, 1970). For example, the perinatal mortality among males of given birthweight tends to be higher than that among females of the same birthweight.

This study was financed initially by a grant from the Nuffield Provincial Hospitals Trust and the analysis was carried out with the support of the Department of Health and Social Security. We are obliged to the staff of the Office of Population, Censuses, and Surveys for assistance with the linkage of the birth records and to the Medical Officers of Health of Cornwall, Devon, Exeter and Plymouth for making their birth notification records available for study.

\section{REFERENCES}

Abernathy, J. R., Greenberg, B. G., Grizzle, J. E., and DoNnelly, J. F. (1966). Birth weight, gestation, and crown-heel length as response variables in multivariate analysis. Amer. J. publ. Hlth, 56, 1281

AsHFORD, J. R. (1970). Epidemiological and biometric issues in infant mortality. Chapter in Key Issues in Infant Mortality, Report of a Conference ,Washington, D.C., April 1969, pp. 9-16. U.S. National Institute of Child Health. 
Brimblecombe, F. S. W. and Fryer, J. G. (1968). Birth weight and perinatal mortality in England and Wales 1956-65. In Problems and Progress in Medical Care, 3rd Series, edited by G. McLachlan, Chapter I. Oxford University Press, London. Published for the Nuffield Provincial Hospitals Trust.

Brimblecombe, F. S. W., Ashford, J. R., and FrYer, J. G. (1968). Significance of low birth weight in perinatal mortality: a study of variations within England and Wales. Brit. J. prev soc. Med., 22, 27.
Butler, N. R. and Alberman, Eva D. (1969). Perinatal Problems: The Second Report of the 1958 British Perinatal Mortality Survey. Livingstone, London and Edinburgh.

FrYeR, J. G. and RoBertson, C. A. (1972). A comparison of some methods for estimating mixed normal distributions. Biometrika, 59, 639.

KAMINSKI, M., GoujaRD, J., and Rumeau-RouquetTe, C. (1973). Prediction of low birth weight and prematurity by a multiple regression analysis with maternal characteristics known since the beginning of the pregnancy. Int. J. Epidem., 2, 195. 